\title{
Metodologia para a análise de assunto de acórdãos no contexto do controle externo: proposta de um modelo de leitura técnica
}

\author{
Ana Carolina Ferreira \\ Doutoranda; Universidade Federal de Minas Gerais, Belo Horizonte, MG, Brasil; \\ anacarolinaf2004c@gmail.com \\ Benildes Coura Moreira dos Santos Maculan \\ Doutora; Universidade Federal de Minas Gerais, Belo Horizonte, MG, Brasil; \\ benildes@gmail.com
}

\begin{abstract}
Resumo: Apresenta parte dos resultados de uma pesquisa de mestrado que investigou o problema da carência de metodologias na literatura da Biblioteconomia e da Ciência da Informação, para a análise de assunto de documentos jurídicos do tipo acórdão. Sendo a análise de assunto essencialmente subjetiva, são necessários procedimentos metodológicos sistematizados para objetivá-la e, assim, obter maior consistência na representação temática da informação. Nesse contexto, a pesquisa teve como objetivo desenvolver uma metodologia para a sistematização da análise de assunto do acórdão, visando minimizar a subjetividade inerente ao processo de análise desse documento durante a leitura técnica. A metodologia adotada na pesquisa foi caracterizada como qualitativa, exploratória e de natureza aplicada, na forma de um estudo de caso, no âmbito do Tribunal de Contas do Estado de Minas Gerais. A partir de aportes teórico-conceituais da Biblioteconomia, Ciência da Informação e Direito, construiu-se um modelo de leitura técnica de acórdãos dos tribunais de contas, cujos fundamentos são a estrutura temática desse documento; a identificação de conceitos essenciais a partir de questionamentos; o uso de estratégias cognitivas e metacognitvas de leitura; e a adoção das categorias de análise temática definidas por Guimarães. Os resultados da pesquisa indicam que a prática sistematizada da análise de assunto pode objetivar o processo de análise ao definir os procedimentos metodológicos para o indexador realizar a atividade.
\end{abstract}

Palavras-chave: Análise de assunto. Indexação. Modelo de leitura técnica. Estratégias de leitura. Acórdão. Tribunal de contas. 
Metodologia para a análise de assunto de acórdãos no contexto do controle externo: proposta de um modelo de leitura técnica

Ana Carolina Ferreira e Benildes Coura Moreira dos Santos Maculan

\section{Introdução}

Este artigo apresenta parte dos resultados de uma pesquisa de mestrado defendida no final de 2017 no Programa de Pós-Graduação em Gestão e Organização do Conhecimento da Escola de Ciência da Informação da Universidade Federal de Minas Gerais (PPG-GOC/ECI/UFMG). O problema de pesquisa foi verificado durante a prática profissional da proponente, na indexação de documentos jurídicos no âmbito do Tribunal de Contas do Estado de Minas Gerais (TCEMG), situação na qual foram identificadas as dificuldades e especificidades da estrutura e da representação temática de tais documentos.

Dado esse problema, também foi observada uma lacuna na literatura da Biblioteconomia e da Ciência da Informação (CI), no que tange à carência de metodologias para a etapa de análise de assunto no processo de indexação (HUTCHINS, 1977; CHU; O’OBRIEN, 1993; LARA, 1993; KOBASCHI, 1994; GUIMARÃES, 1994; NAVES, 2000; FUJITA, 2003; MOURA, 2006; SILVA, 2008; KOBASHI; FERNANDES, 2009; FUJITA, 2013; LIMA; MACULAN, 2014). Em especial, constatou-se essa carência no que se refere à análise de assunto de documentos jurídicos do tipo acórdão, que são produzidos no contexto dos tribunais e refletem o resultado de um julgamento colegiado, apresentando estrutura temática própria, que é definida por uma lei de abrangência nacional, o Código de Processo Civil (BRASIL, 2015). Constatouse que, ao longo de sua história, no campo da representação temática, as investigações nortearam-se pela preocupação com os instrumentos terminológicos, como os tesauros e os vocabulários controlados, empregados na etapa de tradução do processo de indexação, em detrimento dos estudos sobre a etapa de análise de assunto.

Nesse contexto, a pesquisa se propôs a apresentar contribuições para suprir parte dessa carência, a partir da criação de um Modelo de Leitura Técnica (MLT) para a sistematização da etapa de análise de assunto do acórdão, visando minimizar a subjetividade envolvida nesse processo. Esse modelo foi construído a partir de aportes teóricos da Biblioteconomia, da CI e do Direito, e teve como fundamentos o uso de estratégias de leitura para a identificação de conceitos, 


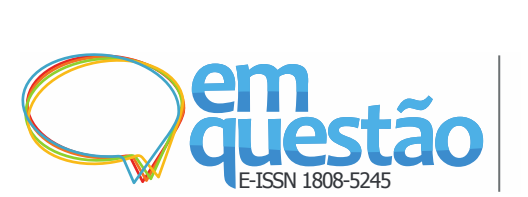

Metodologia para a análise de assunto de acórdãos no contexto do controle externo: proposta de um modelo de leitura técnica

Ana Carolina Ferreira e Benildes Coura Moreira dos Santos Maculan

combinado com a análise da estrutura do documento, a partir a adoção de questionamentos construídos com base em categorias temáticas, definidas, inicialmente, por Guimarães (1994). É importante destacar que o modelo de leitura desenvolvido é uma metodologia ${ }^{1}$ inédita no campo de investigações sobre a análise de assunto de acórdãos no contexto do controle externo ${ }^{2}$.

Dentro dessa perspectiva, este artigo apresenta o Modelo de Leitura Técnica desenvolvido, e está estruturado da seguinte forma: na seção dois, descreve-se a etapa da análise de assunto no contexto da indexação; a seção três apresenta as estratégias de leitura que podem ser usadas pelo indexador durante o processo de análise de assunto; a seção quatro aborda alguns conceitos jurídicos importantes para a compreensão do modelo de leitura técnica que foi construído; na seção cinco, contextualizam-se os procedimentos metodológicos que subsidiaram a construção do modelo de leitura técnica; a seção seis apresenta alguns resultados, análises e discussões da pesquisa; e, finalmente, na seção sete, são tecidas as considerações finais.

\section{A análise de assunto na indexação}

A indexação é um processo técnico que objetiva tornar acessíveis, aos usuários e leitores, por meio de uma representação, o(s) assunto(s) contido(s) nos documentos, tendo em vista a facilitação da comunicação do conhecimento produzido. Todos os objetos são passíveis de representação, que é feita com o propósito de recuperação nos sistemas de informação. Nesse sentido, a indexação também é mediação entre os conteúdos dos documentos, os indexadores e os leitores-usuários.

Tradicionalmente, a literatura de Biblioteconomia e CI divide o processo de indexação em duas etapas: a primeira inclui a análise de assunto, e a segunda a tradução ou transposição dos conceitos identificados na primeira etapa para uma linguagem de indexação, como os tesauros. Não se trata de uma representação perfeita, haja vista que é um processo de redução semântica da informação original, permeado pela necessidade de normalização terminológica, 
Metodologia para a análise de assunto de acórdãos no contexto do controle externo: proposta de um modelo de leitura técnica

Ana Carolina Ferreira e Benildes Coura Moreira dos Santos Maculan

e também, conforme Gomez (1993), por um contexto de ação social, cultural e sócio-político.

A etapa da análise de assunto é complexa e, essencialmente, subjetiva, pois é marcada por diversos fatores como experiência, conhecimentos e valores do indexador, qualidade dos instrumentos terminológicos e por variações que podem ocorrer quando um mesmo indexador, ou indexadores diferentes, atribuem conceitos diversos para um mesmo documento em momentos distintos (NAVES, 2000; NEVES, 2012). Assim, são necessários procedimentos sistematizados para a redução dessa subjetividade na análise de assunto, pois quanto mais compreensão o indexador tem do processo e da subjetividade nele envolvido, melhores as condições de se resolver, metodologicamente, os problemas (FUJITA, 2013).

$\mathrm{Na}$ literatura, a complexidade da análise de assunto também está presente na diversidade terminológica existente em sua identificação, que inclui os termos aboutness (FAIRTHORNE, 1969; HUTCHINS, 1977; INGWERSEN, 1992; NAVES, 2000; DIAS; NAVES, 2013); atinência (LANCASTER, 2004); tematicidade (FUJITA, 2003); análise conceitual e indexação de assuntos (LANCASTER, 2004). Apesar dessas divergências, há uma certa consonância de entendimentos sobre a importância dos estudos sobre a análise de assunto e sobre os conhecimentos que se fazem necessários para se executar tal atividade, como os conhecimentos prévios do domínio a ser representado, a compreensão da estrutura do documento analisado (GUIMARÃES, 1994; KOBASHI, 1994; FUJITA, 2003; SILVA, 2008; MACULAN, 2011), e ter clareza sobre os critérios para a identificação e seleção de conceitos (UNITED NATIONS INFORMATION SYSTEM IN SCIENCE AND TECHNOLOGY, 1981; ASSOCIAÇÃO BRASILEIRA DE NORMAS TÉCNICAS, 1992; FUJITA, 2003).

O documento United Nations Information System In Science And Technology, UNISIST (1981), que contém os princípios para a indexação, define três fases para a etapa da análise de assunto de um documento, que é realizada "Durante a indexação, [quando] os conceitos são extraídos do documento através de um processo de análise [...] [para, então, haver o] 
estabelecimento dos conceitos tratados num documento, isto é, o assunto;" (UNITED NATIONS INFORMATION SYSTEM IN SCIENCE AND TECHNOLOGY, 1981, p. 84-85). Essas fases são:

a) compreensão do conteúdo do documento como um todo;

b) identificação dos conceitos que representam esse conteúdo;

c) seleção dos conceitos válidos para a recuperação.

Já a norma de documentação brasileira, a NBR 12676/1992, divide a etapa da análise de assunto em duas fases, que se sobrepõem: “a) exame do documento e estabelecimento do assunto de seu conteúdo; b) identificação dos conceitos presentes no assunto [...]" (ASSOCIAÇÃO BRASILEIRA DE NORMAS TÉCNICAS, 1992, p. 2). A norma 12676 (ASSOCIAÇÃO BRASILEIRA DE NORMAS TÉCNICAS, 1992) sugere, também, a adoção da abordagem sistemática por questionamentos para a extração de conceitos do documento enquanto o indexador realiza a leitura técnica (intelectual) das partes do texto.

A análise de assunto ocorre, assim, durante a leitura, momento no qual o indexador utiliza estratégias cognitivas e metacognitivas para a compreensão do texto, questões que são discutidas na próxima seção.

\section{Estratégias de leitura}

A leitura é um processo individual de decifração e transposição de signos, constituindo uma atividade abrangente de comunicação, integrada à experiência pessoal do leitor (MOURA, 2006). A leitura é, desse modo, influenciada pelos contextos diversos nos quais o leitor está inserido, sejam eles pessoais ou profissionais, de forma que "A efetivação do gesto de leitura e o sentido pronunciado por cada leitor, individualmente, revelam visões de mundo, experiências pessoais, convenções e pertencimentos sociais distintos." (MOURA, 2006, p. 22). Assim, os conhecimentos e experiências a priori do leitor influenciam a sua leitura.

Durante a compreensão do texto pelo leitor, processos cognitivos e metacognitivos são ativados (KLEIMAN, 1992; KATO, 2007) para permitir o 


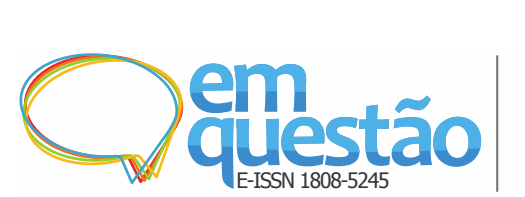

Metodologia para a análise de assunto de acórdãos no contexto do controle externo: proposta de um modelo de leitura técnica

Ana Carolina Ferreira e Benildes Coura Moreira dos Santos Maculan

uso das habilidades cognitivas e dos conhecimentos armazenados pelo leitor na forma de esquemas mentais (RUMELHART, 1980). Assim, no processo de leitura, a teoria cognitiva dos esquemas de Rumelhart (1980), alia-se aos fundamentos teóricos do psicólogo bielo-russo Lev Semenovitch Vygotsky (2009), o qual afirma que a produção do conhecimento apresenta duas fases: a primeira, em que há a aquisição automática e inconsciente desse conhecimento; e a segunda, que inclui uma fase de maior controle consciente das ações cognitivas (KATO, 2007). Essas duas fases da produção do conhecimento são as raízes da tradicional divisão das estratégias de leitura em cognitivas e metacognitivas. Nesse sentido, “A capacidade de estabelecer objetivos na leitura é considerada uma estratégia metacognitiva, isto é, uma estratégia de controle e regulamento do próprio conhecimento [...]" (KLEIMAN, 1992, p. 34, grifo do autor), uma reflexão sobre o próprio saber, que contribui para a compreensão do texto. Kato (2007) argumenta que as estratégias metacognitivas envolvem ações conscientes do leitor frente a um problema e a desautomatização consciente das estratégias cognitivas em situações de problema. Por outro lado, as estratégias cognitivas são inconscientes e automáticas, mas igualmente importantes porque estão relacionadas com os conhecimentos prévios do leitor em relação à língua e ao mundo. Em Kato (2007), para o desenvolvimento das estratégias metacognitivas, dois elementos básicos são necessários: a definição de um objetivo explícito para a leitura e o monitoramento da compreensão para atingir esse objetivo.

Assim, a definição de um objetivo prévio para a leitura permite ao leitor monitorar sua compreensão, tendo em vista o alcance desse objetivo. É nessa discussão teórica que a leitura técnica do profissional indexador se insere, aquela leitura feita com propósitos e objetivos definidos de compreensão do texto, identificação e seleção de conceitos para o processo de análise de assunto num determinado domínio do conhecimento. No contexto da leitura técnica, o conhecimento de estratégias de leitura auxilia o indexador na compreensão do texto, ao constituir-se em um conjunto de ações que permitem ao leitor atribuir sentido ao que é lido. Dentre as estratégias de leitura importantes para aplicação no âmbito da representação temática, situa-se o conhecimento da estrutura 


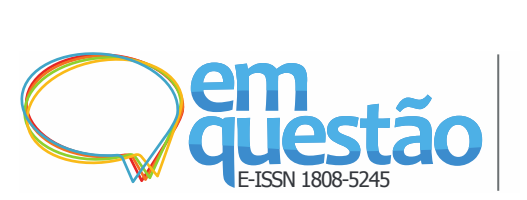

Metodologia para a análise de assunto de acórdãos no contexto do controle externo: proposta de um modelo de leitura técnica

Ana Carolina Ferreira e Benildes Coura Moreira dos Santos Maculan

textual do documento (VAN DIJK, 1988), a denominada macroestrutura, também aplicada em estudos da Biblioteconomia e da CI, como os de Cintra (1987); Tálamo (1987); Farrow (1991); Guimarães (1994); Kobashi (1994); Farrow (1996); Fagundes (2001); Fujita (2003); Fujita e Rubi (2006); Silva (2008) e Maculan (2011).

Os autores Van Dijk e Kintsch (1983) e Van Dijk (1988) desenvolveram a teoria de análise de textos a partir da concepção de superestrutura de documentos para identificar os esquemas textuais, que são úteis para as atividades analíticas de assunto e de representação da informação. Do trabalho dos autores, depreende-se que a identificação de assuntos nos textos é facilitada pela estrutura lógica padrão neles presente. Essa afirmação é enfatizada por Cintra (1987), que diz que:

Os constituintes básicos de um determinado tipo de texto definem a sua superestrutura [a qual permite que] leitores com conhecimento prévio específico sobre superestruturas textuais executem a tarefa de ler de forma mais fácil que leitores que não 'veem' essa superestrutura e por isso são obrigados a um maior apoio na leitura palavra por palavra [...] (CINTRA, 1987, p. 30).

Nesse sentido, "A superestrutura pode ser descrita como um tipo de esquema abstrato que estabelece a ordem global de um texto e que se compõe de uma série de categorias, cujas possibilidades de combinação baseiam-se em regras convencionais." (FUJITA, 2003, p. 85, grifo do autor). No texto científico, por exemplo, o paradigma de organização textual é constituído pelas categorias problema, hipótese, metodologia, resultados e conclusão. Nessa perspectiva, “[...] novos tipos de discursos e formas de conhecimento requerem o desenvolvimento de novas estratégias." (VAN DIJK; KINSTCH, 1983, p. 11).

A construção do sentido da leitura também é influenciada por três elementos inter-relacionados: o leitor, o texto e o contexto (GIASSON, 1993). O leitor é a variável mais complexa dentre esses elementos, porque ele é influenciado por suas estruturas cognitivas, pelo contexto físico, psicológico ou social e pela intenção e motivação da leitura. Por outro lado, o texto, como já discutido, apresenta estruturas e conteúdos próprios. A estrutura refere-se à forma como as ideias se organizam em um texto, enquanto o conteúdo remete o 


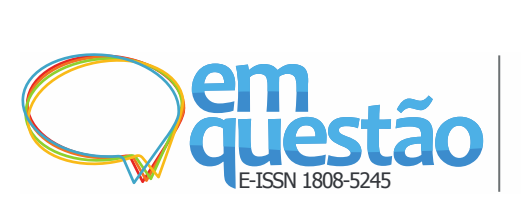

Metodologia para a análise de assunto de acórdãos no contexto do controle externo: proposta de um modelo de leitura técnica

Ana Carolina Ferreira e Benildes Coura Moreira dos Santos Maculan

leitor aos conceitos nele apresentados. De certo modo, a estrutura do texto está ligada ao seu conteúdo, de forma que o autor de um texto escolhe certa estrutura textual que coincida com o conteúdo que deseja transmitir (GIASSON, 1993). A autora ainda argumenta que a variável contexto se refere às condições nas quais se encontra o leitor (com as suas estruturas e processos) quando entra em contato com um texto; tais contextos podem ser o psicológico, o social e o físico.

Outra estratégia importante para a identificação de conceitos durante a leitura técnica refere-se à abordagem por questionamentos segundo categorias temáticas, a exemplo da proposta de Kobashi (1994), que propõe mecanismo de perguntas conceituais oriundas da Teoria da Comunicação de Harold Lasswell (1971): quem? (agente); o quê? (tema); como? (modo); onde? (lugar); quando? (tempo). Essa concepção de abordagem por questionamentos a partir da adoção de categorias temáticas na análise de assunto também foi adotada em investigações na Ciência da Informação por autores como Fagundes (2001); Fujita e Rubi (2006); Silva (2008) e Maculan (2011).

Tendo apresentado aportes teóricos dos campos de Biblioteconomia e CI, em especial quanto aos temas da análise de assunto, indexação e estratégias de leitura, a próxima seção abordará alguns conceitos jurídicos importantes para a compreensão do modelo de leitura que será apresentado mais adiante.

\section{0 acórdão no contexto dos tribunais de contas}

Para situar o assunto, inicia-se com a noção de fontes de informação jurídicas, que são, tradicionalmente, divididas em três tipos: (1) doutrina; (2) legislação; e (3) jurisprudência. Assim, a doutrina jurídica preocupa-se com o caráter científico do Direito e sua expressão documental ocorre por meio dos livros, artigos científicos, pareceres, trabalhos apresentados em anais de eventos e de toda a literatura de cunho teórico-científico. Por sua vez, a legislação constituise de todo o conjunto normativo expedido, caracteristicamente, pelas casas legislativas, aqui incluídas a legislação de âmbito superior, como as constituições, emendas constitucionais, leis complementares e leis ordinárias; 


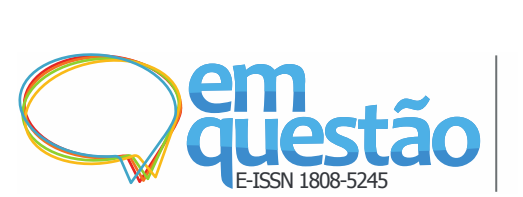

Metodologia para a análise de assunto de acórdãos no contexto do controle externo: proposta de um modelo de leitura técnica

Ana Carolina Ferreira e Benildes Coura Moreira dos Santos Maculan

assim como as normas de hierarquia inferior que podem ser produzidas por outros órgãos governamentais, como as resoluções, portarias e instruções normativas. A função precípua da legislação é definir direitos e estabelecer regras, que são essenciais ao convívio social. Já a jurisprudência constitui-se, em sentido amplo, de todas as decisões produzidas no contexto dos tribunais. No sentido estrito, porém, a jurisprudência refere-se à uniformidade de entendimento de um tribunal sobre uma determinada questão jurídica (NADER, 2014).

No contexto da jurisprudência, que é a fonte de informação de interesse para este estudo, há uma ampla variedade de naturezas processuais e de documentos produzidos. Um tipo de documento nesse conjunto é o acórdão, que, segundo o Novo Código de Processo Civil, NCPC (BRASIL, 2015), referese ao "[...] julgamento colegiado proferido pelos tribunais." (BRASIL, 2015, art. 204). Dessa definição, dois elementos são importantes: a natureza, que se refere ao resultado de um julgamento colegiado, e sua fonte geradora, que são os tribunais (GUIMARÃES, 2004).

No Brasil, destaca-se que há duas tipologias de tribunais: os pertencentes ao poder judiciário e os que exercem o controle externo dos recursos públicos. Este artigo trata deste segundo tipo, que são dos tribunais de contas, os quais, segundo a Constituição Federal de 1988 (BRASIL, 1988), auxiliam o poder legislativo de forma técnica no exercício da fiscalização das contas públicas. Ademais, os tribunais de contas realizam, entre outras atividades decorrentes de suas competências, auditorias; inspeções; monitoramentos; emissão de pareceres prévios; fiscalização de editais de concursos públicos e de procedimentos licitatórios; registro de atos concessórios de aposentadorias, reforma e pensão; e julgamento de contas (BRASIL, 1988, art. 71, II). O controle externo abarca a fiscalização de elementos de ordem financeira, contábil, orçamentária, operacional, patrimonial e dos seus desdobramentos em relação à gestão de recursos públicos por pessoas físicas ou jurídicas. Neste artigo, adota-se o entendimento da doutrina jurídica majoritária de que os tribunais de contas detêm a prerrogativa de ser um órgão estatal de dizer o direito com caráter de definitividade (MIRANDA, 1967; MELO, 2007; FERNANDES, 2012), 


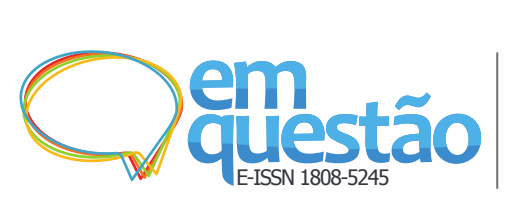

Metodologia para a análise de assunto de acórdãos no contexto do controle externo: proposta de um modelo de leitura técnica

Ana Carolina Ferreira e Benildes Coura Moreira dos Santos Maculan

competência atribuída a tais órgãos pelo art. 71, II, da Constituição Federal de 1988 (BRASIL, 1988). Nesse contexto, o acórdão é fruto dessa função judicante, ainda que haja autores contrários à concepção do exercício da jurisdição pelos tribunais de contas (GUALAZZI, 1992; MANCUSO, 2010), conforme é discutido em Ferreira (2017).

Cabe destacar que o acórdão apresenta uma estrutura pré-determinada pelo NCPC (BRASIL, 2015), segundo a qual o documento deve ser composto por relatório, fundamentação e dispositivo (BRASIL, 2015, art. 489). No relatório, apresenta-se a identificação do caso, um pequeno histórico da tramitação e do andamento processual, assim como os nomes das partes. Já a fundamentação é analítica e argumentativa, e nela são expostos os motivos da decisão, os fundamentos normativos, jurisprudenciais e doutrinários nos quais o relator do processo se pautou para definir sua decisão, uma vez que todas as decisões devem ser fundamentadas, sob pena de nulidade absoluta. Por sua vez, o dispositivo contém o conteúdo decisório, a conclusão do julgador a partir do que foi apresentado no relatório e na fundamentação. Assim, essa estrutura prévia para o acórdão, decorrente de uma lei de aplicabilidade nacional, sugere certa facilidade para realizar a indexação desse tipo de documento, ao se identificar a informação pertinente a cada parte. Essa estrutura orientou a criação do Modelo de Leitura, cujos procedimentos estão apresentados a seguir.

\section{Procedimentos metodológicos}

A pesquisa se caracterizou como exploratória, de abordagem qualitativa, essencialmente interpretativa e de natureza aplicada, com procedimento técnico de um estudo de caso no âmbito do Tribunal de Contas do Estado de Minas Gerais (TCEMG). A elaboração do Modelo de Leitura Técnica foi realizada em duas fases:

Primeira Fase, foram feitas buscas bibliográficas em bases de dados nacionais e internacionais da Biblioteconomia, da Ciência da Informação e do Direito, sobre temáticas afins à indexação da jurisprudência e de acórdãos - os quais constituem subconjuntos de documentos jurisprudenciais - sem 


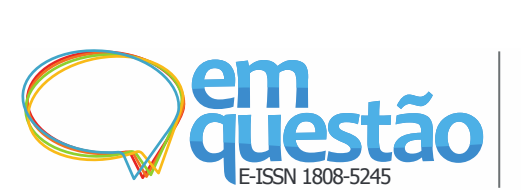

Metodologia para a análise de assunto de acórdãos no contexto do controle externo: proposta de um modelo de leitura técnica

Ana Carolina Ferreira e Benildes Coura Moreira dos Santos Maculan

delimitação de recorte temporal. As buscas bibliográficas foram feitas nas bases de dados: Base de Dados Referencial da Assembleia Legislativa de Minas Gerais (ALMG); Base de Dados Referencial de Artigos de Periódicos em Ciência da Informação (Brapci); Base Peri (ECI/UFMG); Biblioteca Digital Fórum de Direito Público; Directory of Open Access Journals (DOAJ); Google Acadêmico; Portal de Periódicos da Capes; Scientific Electronic Library Online (SciELO); Portais de revistas da área; Sistema de Informações do Congresso Nacional (Sicon) e Sistema Pergamum (ECI/UFMG). Como estratégia de busca, ainda na primeira fase, utilizaram-se as seguintes expressões: modelo de leitura técnica and documento jurídico; model of technical reading; leitura documentária and documento jurídico; indexação assunto document\$ jurídic\$; indexação da jurisprudência (com e sem aspas); indexação da jurisprudência dos tribunais de contas (com e sem aspas); documentação jurídica; organização da informação jurídica; organização temática and informação jurídica; organização temática and documento jurídico; biblioteconomia jurídica; fontes de informação jurídica; organization of legal information; legal documentation; jurisprudence; model for conceptual analysis; subject analysis; conceptual analysis; "recuperação da informação jurídica"; informação jurídica; análise de assunto; leitura técnica; legal documentation; indexação e variantes (exemplo: indexação and documento not economia; indexação not economia); informação jurídica recuperação; linguagem de indexação; jurisprudência indexação.

Segunda Fase, foi realizada a seleção e análise dos trabalhos recuperados na primeira fase, a partir dos seguintes critérios:

a) publicações relacionadas ao tema da indexação manual/intelectual de acórdãos, que foram identificadas a partir dos critérios de busca para a localização de documentos sobre 'indexação da jurisprudência', haja vista que os acórdãos são um subconjunto de documentos no contexto da jurisprudência;

b) manuais com orientações sobre indexação de acórdãos, também identificados de acordo com os critérios apontados no item 1;

c) trabalhos sobre indexação automática da jurisprudência e de acórdãos; 


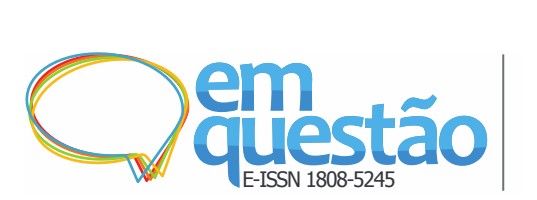

Metodologia para a análise de assunto de acórdãos no contexto do controle externo: proposta de um modelo de leitura técnica

Ana Carolina Ferreira e Benildes Coura Moreira dos Santos Maculan

d) documentos sobre ementas ${ }^{3}$, identificados a partir dos critérios de busca referentes à organização temática da informação jurídica; nesse último caso, é preciso considerar que a ementa é um tipo de resumo jurisprudencial e compõe a estrutura temática do acórdão.

Ademais, há uma aproximação conceitual e metodológica entre a indexação e a elaboração de resumos (KOBASHI, 1994; LANCASTER, 2004), o que justifica a inclusão das ementas como objeto de estudo na pesquisa realizada.

Assim, dentre os documentos recuperados, foram identificados e selecionados, ao todo, 26 trabalhos, dos quais foram distinguidos aqueles que abordaram a temática da indexação manual, num total de sete trabalhos: Atienza (1979, 1981); Mourão e Mastro, (1989); Guimarães (1994); Brasil (1996, 2002) e Silva (2008).

Decidiu-se, também, pela inclusão dos Manuais - Manual de indexação da justiça federal, do Conselho da Justiça Federal (BRASIL, 1996), e do Manual do analista de jurisprudência, do Superior Tribunal de Justiça, (BRASIL, 2002) -, com orientações teórico-práticas para a indexação de acórdãos, por razões de relevância desse tipo de documento no processo de análise de assunto de acórdãos. Ademais, foi incluída a publicação de Guimarães (2004), sobre elaboração de ementas, que apresenta adaptações terminológicas das quatro categorias temáticas para a análise de assunto de acórdãos (fato, instituto jurídico, entendimento e argumento), a partir dos princípios teóricos advindos de sua tese (GUIMARÃES, 1994). Essas categorias temáticas foram adaptadas, em termos conceituais e terminológicos, para o contexto dos acórdãos e ementas produzidas pelos tribunais de contas por Pimentel (2015) e Barbosa Netto e Cunha (2015), estudos que também nortearam a construção do Modelo de Leitura. É importante destacar que a literatura que subsidiou a construção do MLT, considerada como os insumos teórico-metodológicos (subseção 6.1), foi, essencialmente, nacional, em virtude das peculiaridades do estudo de caso. Além disso, o acórdão considerado como objeto de investigação foi o produzido no contexto brasileiro, e cuja estrutura deriva de uma lei de abrangência nacional, o Código de Processo Civil. 


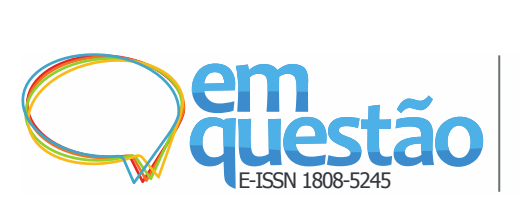

Metodologia para a análise de assunto de acórdãos no contexto do controle externo: proposta de um modelo de leitura técnica

Ana Carolina Ferreira e Benildes Coura Moreira dos Santos Maculan

Tendo apresentado os procedimentos de investigação, a próxima seção apresenta os resultados, análises e discussões sobre o modelo de leitura propriamente dito, define a sua estrutura e faz a sua validação.

\section{Resultados, análises e discussões}

Esta seção apresenta os insumos teórico-metodológicos que subsidiaram o desenvolvimento do Modelo de Leitura Técnica, relata a sua estrutura e especificidades, além de aplicá-lo e validá-lo em uma denúncia produzida pelo Tribunal de Contas do Estado de Minas Gerais (TCEMG).

\subsection{Apresentação dos insumos teórico-metodológicos}

A partir do mapeamento da literatura, observa-se que a concepção de representação temática de acórdãos com o uso de fichas (ATIENZA, 1981; MOURÃO; MASTRO, 1989) evoluiu para a adoção de categorias temáticas na análise (fato, instituto jurídico, entendimento e argumento) (GUIMARÃES, 1994, 2004).

Verificou-se, também, que o tema da indexação automática de acórdãos, seja com o uso de inteligência artificial (HAFNER, 1987; BRAGA JÚNIOR, 2001; FRANCESCONI; PERUGINELLI, 2009; OLIVEIRA, 2008; ALABDULKARIM; ATKINSON; BENCH-CAPON, 2016; PALIWALA, 2016; TAAL et al., 2016; VERHEIJ, 2016), pela abordagem do processamento de linguagem natural (CÂMARA JÚNIOR, 2007), text mining (STRANIERI et al., 1999; RIBEIRO, 2010; MOLINARI, 2011); ou linked data (AGNOLONI et al., 2013); é abordado em investigações nesse campo de estudos. Embora se reconheça a importância da indexação automática no tratamento de amplos volumes de dados, os resultados da pesquisa apresentados neste artigo tiveram como norte a abordagem manual/intelectual para a análise e indexação de acórdãos. 


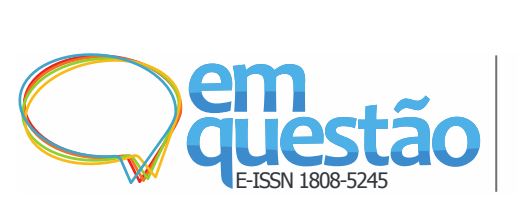

Metodologia para a análise de assunto de acórdãos no contexto do controle externo: proposta de um modelo de leitura técnica

Ana Carolina Ferreira e Benildes Coura Moreira dos Santos Maculan

Ainda no levantamento da literatura, observou-se que alguns trabalhos utilizaram as categorias temáticas propostas por Guimarães (1994, 2004) como fundamento para suas investigações (BRASIL, 1996, 2002; MAÇOLI, 2005; PIMENTEL, 2015; BARBOSA NETTO; CUNHA, 2015). Essas categorias, intituladas fato, instituto jurídico, entendimento e argumento, foram criadas por Guimarães (1994), a partir da Teoria Tridimensional do Direito ${ }^{4}$, do jusfilósofo brasileiro Miguel Reale (1994).

Nessa perspectiva, o significado da categoria fato jurídico pode ser entendido como "[...] todo fato material que produz efeitos jurídicos; vale dizer, fatos de cuja ocorrência nascem, modificam-se ou extinguem-se direitos, adquirindo, pois, relevância jurídica.” (GUIMARÃES, 1994, p. 186). A identificação da categoria fato não se refere a uma ação específica, com agente e paciente, mas a uma situação fática de natureza genérica, cujas características podem se repetir em outros contextos, gerando situações fáticas de mesmo teor, argumenta Guimarães (1994).

Houve uma adaptação terminológica da categoria instituto jurídico, do trabalho de Guimarães (2004) sobre ementas, para questão jurídica. Essa terminologia é corroborada por Pimentel (2015) e Barbosa Netto e Cunha (2015), que a estabeleceram para aplicabilidade ao contexto e às especificidades dos tribunais de contas, denominando-a como questão jurídica ou técnica.

Por sua vez, a categoria temática entendimento diz respeito ao elo entre o fato e o direito discutido, e se reflete no posicionamento do órgão julgador para o fato analisado em relação às pretensões das partes. O entendimento dever ser motivado e " $[\ldots]$ apresenta caráter dual, pois o nexo a ser estabelecido entre o fato e o instituto jurídico só pode ser positivo (existente) ou negativo (inexistente). (GUIMARÃES, 1994, p. 196), pois “[...] decorre do reconhecimento ou não de um direito, da legalidade ou não de uma conduta ou mesmo da legalidade ou constitucionalidade de uma norma [...] (BARBOSA NETTO; CUNHA, 2015, p. 46). Assim, no contexto do controle externo, o entendimento pode ser identificado pelas expressões: "é ilegal”; “é irregular"; “é lícito" (BARBOSA NETTO; CUNHA, 2015). Por fim, a categoria argumento ou fundamento refere-se às razões que sustentam o entendimento, ou seja, é 
Metodologia para a análise de assunto de acórdãos no contexto do controle externo: proposta de um modelo de leitura técnica

Ana Carolina Ferreira e Benildes Coura Moreira dos Santos Maculan

uma atividade basicamente persuasiva, devendo ser acompanhada de argumentação e justificativa para o posicionamento adotado no acórdão. (GUIMARÃES, 1994; BARBOSA NETTO; CUNHA, 2015).

Assim, a partir das discussões expostas, considerou-se que a proposta de análise de assunto por categorias apresentada em Guimarães $(1994,2004)$ seria relevante para subsidiar, também, a construção do Modelo de Leitura Técnica, cuja estrutura está apresentada na próxima seção.

\subsection{Apresentação do modelo de leitura técnica: estrutura e fundamentos conceituais}

Nesta seção, apresentam-se a estrutura e os fundamentos do Modelo de Leitura Técnica, o qual se destina ao bibliotecário-indexador que não possui formação jurídica, mas que tenha experiência e conhecimentos decorrentes de atuação no âmbito do controle externo. O Modelo de Leitura pode, desse modo, auxiliar na análise de assunto, mas não resolve problemas de compreensão de termos técnicos jurídicos, que se pressupõe serem de domínio do indexador.

Assim, conforme o Quadro 1, o Modelo de Leitura Técnica foi estruturado em quatro colunas e oito linhas. A primeira coluna indica a parte da estrutura do acórdão que deve ser analisada pelo indexador, aqui incluída a ementa, o relatório, a fundamentação (preliminar e de mérito), o voto e o acórdão stricto sensu. Essas partes temáticas do acórdão devem ser confrontadas com a abordagem por questionamentos da segunda coluna, tendo como parâmetro a análise de assunto por categorias identificadas na terceira coluna, para, então, haver o estabelecimento dos conceitos identificados na quarta coluna. Cada linha do modelo explicita a parte temática do acórdão, e apresenta o significado de cada elemento de sua estrutura com exemplos práticos.

Ademais, nas três últimas linhas do Modelo de Leitura, deverão ser sistematizados os conceitos identificados em cada parte temática. Assim, na linha Seleção dos conceitos / Frase de indexação, os conceitos selecionados devem ser organizados em uma frase de indexação ${ }^{5}$ de acordo com a ordem de citação sugerida. Já na linha Seleção dos conceitos referentes às 


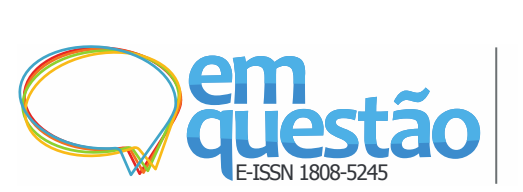

Metodologia para a análise de assunto de acórdãos no contexto do controle externo: proposta de um modelo de leitura técnica

Ana Carolina Ferreira e Benildes Coura Moreira dos Santos Maculan

recomendações / Frase de indexação devem ser inseridos os conceitos selecionados a partir dos conceitos identificados sobre as recomendações que o Tribunal de Contas faz ao fiscalizado. Os conceitos referentes às recomendações devem ser organizados de forma lógica, a partir da elaboração de uma frase com sentido compreensível para o leitor. Por fim, na última linha do modelo, o indexador deve indicar as fontes de informação jurídicas (legislativas, doutrinárias e jurisprudenciais) que fundamentaram a decisão.

O Modelo de Leitura Técnica foi concebido em observância às fases da análise de assunto identificadas na literatura, que inclui a compreensão do acórdão como um todo, realizada a partir da leitura técnica, da identificação de conceitos (explicitada na coluna quatro) e da seleção de conceitos (na antepenúltima e penúltima linha). Na construção do Modelo de Leitura, também foi adotada a concepção de estrutura do documento de Van Dijk (1988) e de Giasson (1993), corroborada por autores da Ciência da Informação como Kobashi (1994), Guimarães (1994), Fagundes (2001), Fujita (2003), Fujita e Rubi (2006), Silva (2008) e Maculan (2011).

Quadro 1 - Modelo de Leitura Técnica para acórdãos dos tribunais de contas

\begin{tabular}{|c|c|c|c|}
\hline $\begin{array}{c}\text { PARTE TEMÁTICA DO } \\
\text { ACÓRDÃO A } \\
\text { ANALISAR }\end{array}$ & QUESTIONAMENTOS & $\begin{array}{l}\text { CONCEITOS } \\
\text { ESSENCIAIS }\end{array}$ & $\begin{array}{l}\text { CONCEITOS } \\
\text { IDENTIFICADOS }\end{array}$ \\
\hline $\begin{array}{l}\text { EMENTA (parte na qual se } \\
\text { localiza uma breve } \\
\text { apresentação do conteúdo } \\
\text { essencial do acórdão) }\end{array}$ & $\begin{array}{l}\text { Qual a questão jurídica ou } \\
\text { técnica? } \\
\text { Qual foi a proposta ou aquilo } \\
\text { que foi proposto e } \\
\text { apresentado como tema a ser } \\
\text { discutido e julgado? } \\
\text { A questão técnica ou jurídica } \\
\text { reflete a matéria objeto da } \\
\text { discussão. } \\
\text { Exemplo: na prestação de } \\
\text { contas dos ordenadores de } \\
\text { despesa, tem-se a questão } \\
\text { jurídica: "julgamento da } \\
\text { prestação de contas" }\end{array}$ & $\begin{array}{l}\text { Questão jurídica } \\
\text { ou técnica }\end{array}$ & $\begin{array}{l}\text { Pode-se utilizar a } \\
\text { linguagem natural } \\
\text { do documento }\end{array}$ \\
\hline $\begin{array}{l}\text { RELATÓRIO (parte do } \\
\text { acórdão em que se } \\
\text { encontram as narrativas dos } \\
\text { fatos ocorridos no } \\
\text { andamento processual) }\end{array}$ & $\begin{array}{c}\text { Qual a situação fática? } \\
\text { O que aconteceu? } \\
\text { A situação fática envolve os } \\
\text { fatos jurídicos, que produzem } \\
\text { efeitos jurídicos, como o } \\
\text { surgimento, a modificação ou a } \\
\text { extinção de direitos. } \\
\text { Exemplo: realização de pregão } \\
\text { presencial, na Prefeitura de } \\
\text { Campos Gerais, no ano de } \\
\text { 2017, para a aquisição de }\end{array}$ & Situação fática & \\
\hline
\end{tabular}


Metodologia para a análise de assunto de acórdãos no contexto do controle externo: proposta de um modelo de leitura técnica

Ana Carolina Ferreira e Benildes Coura Moreira dos Santos Maculan

\begin{tabular}{|c|c|c|c|}
\hline $\begin{array}{c}\text { PARTE TEMÁTICA DO } \\
\text { ACÓRDÃO A } \\
\text { ANALISAR }\end{array}$ & QUESTIONAMENTOS & $\begin{array}{l}\text { CONCEITOS } \\
\text { ESSENCIAIS }\end{array}$ & $\begin{array}{l}\text { CONCEITOS } \\
\text { IDENTIFICADOS }\end{array}$ \\
\hline & $\begin{array}{l}\text { pneus, que sugere indícios de } \\
\text { irregularidades. }\end{array}$ & & \\
\hline $\begin{array}{l}\text { FUNDAMENTAÇÃO - } \\
\text { PRELIMINAR E DE } \\
\text { MÉRITO - (também } \\
\text { denominada motivação, é a } \\
\text { parte que resulta da análise } \\
\text { feita pelo relator sobre as } \\
\text { questões de fato e de direito } \\
\text { expostas no relatório) }\end{array}$ & $\begin{array}{c}\text { Quais são as questões } \\
\text { preliminares relevantes que } \\
\text { ocasionaram impacto no } \\
\text { processo? } \\
\text { Exemplo: a discussão sobre a } \\
\text { aplicabilidade do instituto } \\
\text { jurídico da prescrição em um } \\
\text { processo de fiscalização. } \\
\text { Qual(is) a(s) irregularidade(s) } \\
\text { apontada(s) que foi(ram) } \\
\text { considerada(s) pelo relator? } \\
\text { Considerar aqui as análises } \\
\text { finais do relator. } \\
\text { Exemplo: ausência de ampla } \\
\text { divulgação do edital de um } \\
\text { concurso público. } \\
\text { Quais os argumentos? (os } \\
\text { argumentos são as razões que } \\
\text { determinaram o convencimento } \\
\text { do relator acerca da decisão } \\
\text { tomada) } \\
\text { Exemplo: o princípio da } \\
\text { publicidade é condição de } \\
\text { validade do ato administrativo. }\end{array}$ & $\begin{array}{c}\text { Questões } \\
\text { preliminares }\end{array}$ & $\begin{array}{l}\text { Pode-se utilizar a } \\
\text { linguagem natural } \\
\text { do documento }\end{array}$ \\
\hline $\begin{array}{l}\text { VOTO - } \\
\text { CONCLUSÃO/DECISÃO } \\
\text { - (parte em que são } \\
\text { apresentadas as conclusões } \\
\text { do relator) }\end{array}$ & $\begin{array}{l}\text { Qual o entendimento? } \\
\text { O entendimento revela a } \\
\text { posição do relator sobre a } \\
\text { questão em debate e será, } \\
\text { necessariamente, positivo ou } \\
\text { negativo. } \\
\text { Exemplo: é irregular; é lícito; é } \\
\text { legal. } \\
\text { Qual a decisão final? } \\
\text { A decisão final indica o } \\
\text { resultado do entendimento do } \\
\text { relator. Exemplos: determinar o } \\
\text { arquivamento dos autos, aplicar } \\
\text { multa, negar o provimento de } \\
\text { um recurso. }\end{array}$ & $\begin{array}{l}\text { Entendimento } \\
\text { do relator } \\
\text { Decisão do } \\
\text { relator }\end{array}$ & $\begin{array}{l}\text { Pode-se utilizar a } \\
\text { linguagem natural } \\
\text { do documento }\end{array}$ \\
\hline $\begin{array}{l}\text { ACÓRDÃO stricto sensu } \\
\text { (parte que veicula a } \\
\text { conclusão do colegiado de } \\
\text { julgadores) }\end{array}$ & $\begin{array}{l}\text { Quais são as recomendações? } \\
\text { As recomendações constituem } \\
\text { orientações para o gestor } \\
\text { público e são características } \\
\text { específicas dos acórdãos dos } \\
\text { tribunais de contas. As } \\
\text { recomendações são recorrentes } \\
\text { nas inspeçôes ordinárias e nas } \\
\text { prestações de contas, mas não } \\
\text { constituem um item obrigatório. } \\
\text { Exemplo: recomendar ao } \\
\text { prefeito a disponibilização e a } \\
\text { organização de documentos } \\
\text { conforme prescrito em } \\
\text { instrução normativa do } \\
\text { Tribunal. } \\
\text { Qual o entendimento? } \\
\text { O entendimento revela a }\end{array}$ & $\begin{array}{c}\text { Recomendações } \\
\text { Entendimento } \\
\text { do colegiado } \\
\text { Decisão do } \\
\text { colegiado }\end{array}$ & \\
\hline
\end{tabular}


Metodologia para a análise de assunto de acórdãos no contexto do controle externo: proposta de um modelo de leitura técnica

Ana Carolina Ferreira e Benildes Coura Moreira dos Santos Maculan

\begin{tabular}{|c|c|c|c|}
\hline $\begin{array}{c}\text { PARTE TEMÁTICA DO } \\
\text { ACÓRDÃO A } \\
\text { ANALISAR }\end{array}$ & QUESTIONAMENTOS & $\begin{array}{l}\text { CONCEITOS } \\
\text { ESSENCIAIS }\end{array}$ & $\begin{array}{l}\text { CONCEITOS } \\
\text { IDENTIFICADOS }\end{array}$ \\
\hline & $\begin{array}{c}\text { posição do colegiado sobre a } \\
\text { questão em debate e será, } \\
\text { necessariamente, positivo ou } \\
\text { negativo. } \\
\text { Exemplo: é irregular; é lícito; é } \\
\text { legal. } \\
\text { Qual a decisão final? } \\
\text { A decisão final indica o } \\
\text { resultado do entendimento do } \\
\text { colegiado. Na decisão } \\
\text { colegiada, os demais julgadores } \\
\text { podem acompanhar ou não o } \\
\text { voto do relator. } \\
\text { Exemplos: aplicar multa, } \\
\text { determinar a restituição de } \\
\text { valores aos cofres públicos, } \\
\text { determinar o cadastro do nome } \\
\text { do agente político na lista dos } \\
\text { candidatos inelegíveis. }\end{array}$ & & \\
\hline \multicolumn{4}{|c|}{$\begin{array}{l}\text { SELEÇÃO DOS CONCEITOS / FRASE DE INDEXAÇÃO: (nesta parte são apresentados os } \\
\text { conceitos selecionados, em uma ordem que facilita a compreensão e o entendimento do leitor sobre os } \\
\text { principais assuntos e conclusões do acórdão). Sugere-se adotar a ordem de citação proposta por } \\
\text { Guimarães (1994): 1) Instituto Jurídico, que nos processos de controle será concebido como Questão } \\
\text { Jurídica ou Técnica; 2) Fato (Contexto fático); 3) Entendimento; 4) Argumento e, conforme proposta da } \\
\text { autora desta pesquisa, 5) Decisão final. }\end{array}$} \\
\hline \multicolumn{4}{|c|}{$\begin{array}{l}\text { SELEÇÃO DOS CONCEITOS REFERENTES ÃS RECOMENDAÇÕES* / FRASE DE } \\
\text { INDEXAÇÃO: } \\
\text { (nesta parte são apresentados os conceitos selecionados, em uma ordem de citação que facilite a } \\
\text { compreensão e o entendimento do leitor sobre as recomendações feitas pelo relator) }\end{array}$} \\
\hline \multicolumn{4}{|c|}{$\begin{array}{l}\text { FONTES DE INFORMAÇÃO JURÍDICAS: (são as fontes legislativa, jurisprudencial e doutrinária } \\
\text { utilizadas na fundamentação da decisão) }\end{array}$} \\
\hline
\end{tabular}

Fonte: Ferreira (2017, p. 144).

Nota: * As recomendações compõem um campo à parte no Modelo e não são representadas junto com os conceitos principais, tendo em vista sua alta recorrência nos processos de controle externo e também com o objetivo de indicar, de modo mais claro e reduzido, no campo principal, os assuntos essenciais referentes ao acórdão.

Observa-se, pelo Quadro 1, que a organização do Modelo de Leitura pauta-se na estrutura do acórdão, cujas partes básicas são: relatório, fundamentação e dispositivo (BRASIL, 2015, art. 489). Na coluna dois, verificase a aplicação da abordagem sistemática por questionamentos proposta na NBR 12676 (ASSOCIAÇÃO BRASILEIRA DE NORMAS TÉCNICAS, 1992), que define regras para a prática normalizada da análise de assunto, a partir da identificação de conceitos essenciais, conforme Fujita e Rubi (2006). A concepção do modelo de leitura também contou com a abordagem prática presente nos manuais de indexação (BRASIL, 1996, 2002), que trazem o contexto sociocognitivo de trabalho do indexador (FUJITA, 2003).

Parte dos conceitos essenciais localizados na terceira coluna evocam as categorias temáticas propostas por Guimarães (1994, 2004), mas com 
Metodologia para a análise de assunto de acórdãos no contexto do controle externo: proposta de um modelo de leitura técnica

Ana Carolina Ferreira e Benildes Coura Moreira dos Santos Maculan

adaptações terminológicas, já discutidas neste artigo. Por sua vez, em observância às especificidades dos processos de controle externo e às competências constitucionais dos tribunais de contas, aliadas à experiência de indexação de acórdãos no âmbito do TCEMG, outros conceitos essenciais para a análise de assunto desse documento foram propostos. Esses conceitos são: irregularidades e recomendações. Isso porque a fiscalização das irregularidades na gestão dos recursos públicos condiz com um dos pressupostos básicos para a atuação dos tribunais de contas, aspecto refletido nos acórdãos, que são um dos produtos desse processo fiscalizatório. Por sua vez, as recomendações, como já destacado anteriormente, possuem o caráter de orientação ao gestor público.

Observam-se, ainda, três novos conceitos na coluna três, que são: questões preliminares, entendimento do relator/decisão do relator, entendimento do colegiado/decisão do colegiado. Nesse contexto, as questões preliminares compõem, junto com a(s) questão(ões) de mérito, a fundamentação e/ou motivação presente no acórdão e resultam da análise feita pelo relator sobre as questões de fato e de direito expostas no relatório. Assim, uma questão preliminar, que pode ser identificada em um acórdão, é a aplicabilidade da prescrição a um processo de controle externo, por exemplo. De fato, como o nome indica, a questão preliminar é discutida antes da questão principal, a qual diz respeito ao mérito ou irregularidades fiscalizadas nos processos de controle.

Além disso, a separação das expressões entendimento do relator/decisão do relator, entendimento do colegiado/decisão do colegiado indica que o entendimento do relator, refletido em sua decisão, pode ou não ser acompanhado pelo colegiado. Isso quer dizer que o entendimento do relator (aquele que relata o processo) pode ou não ser acompanhado pelos demais membros que compõem a câmara ou outra instância colegiada, pois sua proposta de voto é submetida, nesse contexto, ao aval dos demais membros, que podem ter o mesmo entendimento sobre uma questão jurídica ou não. 


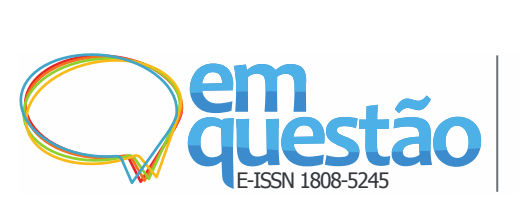

Metodologia para a análise de assunto de acórdãos no contexto do controle externo: proposta de um modelo de leitura técnica

Ana Carolina Ferreira e Benildes Coura Moreira dos Santos Maculan

A validação do modelo foi feita em três acórdãos de quatro naturezas processuais (denúncia, inspeção ordinária, prestação de contas dos ordenadores de despesa e tomada de contas especial) do TCEMG, conforme pode ser encontrado em Ferreira (2017). Para este artigo, a próxima seção mostra a validação do Modelo de Leitura em um acórdão de natureza processual do tipo denúncia.

\subsection{Aplicação e validação do modelo de leitura técnica}

A aplicação e a validação do modelo de leitura foram feitas na denúncia $n$. 837101/2018, apreciada pelo TCEMG, e cuja ementa foi publicada no Diário Oficial de Contas de 18 de junho de 2018.

Trata-se de uma denúncia formulada pela Associação dos Amigos de Araçuaí, para a apuração de possíveis irregularidades na gestão da prefeitura municipal do mesmo município, no período de janeiro a março de 2009. A partir da denúncia apresentada, o TCEMG realizou inspeção extraordinária para verificação, in loco, das ocorrências apontadas pelo denunciante. Quando da realização dessa inspeção, no entanto, houve “[...] comprovada obstrução ao livre exercício da fiscalização do Tribunal de Contas [...]”" (MINAS GERAIS, 2018, online), segundo o relator, corroborado pela segunda câmara. Desse fato, decorreu a aplicação de multa ao ex-prefeito, no valor de $\mathrm{R} \$ 15.000,00$, com fundamento na prerrogativa de o Tribunal poder aplicar multa, de acordo com os casos tipificados no art. 85, IV da Lei Complementar Estadual mineira n. 102 (MINAS GERAIS, 2008). Além da aplicação de multa, a infração cometida pelo ex-prefeito, de dificultar o exercício do controle externo, foi considerada grave, e, por isso, a penalidade foi cumulativa com a declaração de inabilitação do agente público para o exercício de cargo em comissão ou função de confiança da administração pública estadual e municipal, consoante o disposto no art. 83, II, c/c o art. 92 (MINAS GERAIS, 2008) da Lei Complementar supracitada. A determinação do relator de declaração da inabilitação do ex-prefeito foi acolhida pelo Tribunal Pleno, que congrega a maioria absoluta dos membros do Tribunal 


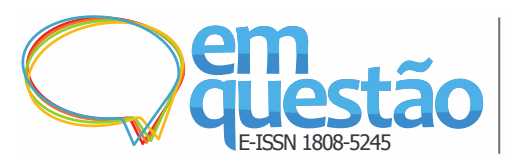

Metodologia para a análise de assunto de acórdãos no contexto do controle externo: proposta de um modelo de leitura técnica

Ana Carolina Ferreira e Benildes Coura Moreira dos Santos Maculan

de Contas. Determinou-se, ainda, a expedição de ofício ao Ministério Público

Estadual para ciência do teor da decisão. Veja, no Quadro 2, a aplicação do modelo de leitura técnica nessa denúncia.

Quadro 2 - Aplicação e validação do modelo de leitura técnica

\begin{tabular}{|c|c|c|c|}
\hline $\begin{array}{c}\text { PARTE TEMÁTICA DO } \\
\text { ACÓRDÃO A } \\
\text { ANALISAR } \\
\end{array}$ & QUESTIONAMENTOS & $\begin{array}{l}\text { CONCEITOS } \\
\text { ESSENCIAIS }\end{array}$ & $\begin{array}{c}\text { CONCEITOS } \\
\text { IDENTIFICADOS }\end{array}$ \\
\hline $\begin{array}{l}\text { EMENTA (parte na qual se } \\
\text { localiza uma breve } \\
\text { apresentação do conteúdo } \\
\text { essencial do acórdão) }\end{array}$ & $\begin{array}{l}\text { Qual a questão jurídica } \\
\text { ou técnica? } \\
\text { Análise da denúncia } \\
\text { sobre a existência de } \\
\text { possíveis irregularidades } \\
\text { na gestão da prefeitura do } \\
\text { município de Araçuaí. }\end{array}$ & $\begin{array}{l}\text { Questão } \\
\text { jurídica ou } \\
\text { técnica }\end{array}$ & $\begin{array}{l}\text { Denúncia, } \\
\text { irregularidade, } \\
\text { gestão, prefeitura, } \\
\text { município, Araçuaí. }\end{array}$ \\
\hline $\begin{array}{l}\text { RELATÓRIO (parte do } \\
\text { acórdão em que se } \\
\text { encontram as narrativas dos } \\
\text { fatos ocorridos no } \\
\text { andamento processual) }\end{array}$ & $\begin{array}{l}\text { Qual a situação fática? } \\
\text { O que aconteceu? } \\
\text { Denúncia formulada pela } \\
\text { Associação dos Amigos } \\
\text { de Araçuaí, sobre } \\
\text { irregularidades na gestão } \\
\text { da prefeitura municipal } \\
\text { de Araçuaí, na gestão } \\
\text { 2009-2012, } \\
\text { posteriormente } \\
\text { convertida em inspeção } \\
\text { extraordinária do } \\
\text { Tribunal de Contas. } \\
\text { Durante a inspeção, foi } \\
\text { comprovada a obstrução } \\
\text { ao livre exercício da } \\
\text { fiscalização. }\end{array}$ & Situação fática & $\begin{array}{c}\text { Denúncia, } \\
\text { formulação, } \\
\text { Associação dos } \\
\text { Amigos de Araçuaí, } \\
\text { irregularidade, } \\
\text { gestão, prefeitura } \\
\text { municipal, Araçuaí. } \\
\text { Realização, } \\
\text { inspeção } \\
\text { extraordinária. } \\
\text { Obstrução, } \\
\text { fiscalização, } \\
\text { TCEMG }\end{array}$ \\
\hline $\begin{array}{l}\text { FUNDAMENTAÇÃO - } \\
\text { PRELIMINAR E DE } \\
\text { MÉRITO - (também } \\
\text { denominada motivação, é a } \\
\text { parte que resulta da análise } \\
\text { feita pelo relator sobre as } \\
\text { questões de fato e de direito } \\
\text { expostas no relatório) }\end{array}$ & $\begin{array}{c}\text { Quais são as questões } \\
\text { preliminares relevantes } \\
\text { que ocasionaram } \\
\text { impacto no processo? } \\
\text { Não há, neste caso } \\
\text { específico. Qual(is) a(s) } \\
\text { irregularidade(s) } \\
\text { apontada(s) que } \\
\text { foi(ram) considerada(s) } \\
\text { pelo relator? } \\
\text { Verificou-se a obstrução } \\
\text { ao exercício da } \\
\text { fiscalização do Tribunal } \\
\text { de Contas, em razão da } \\
\text { ausência de arquivos, } \\
\text { documentos, dados e } \\
\text { sistemas informatizados } \\
\text { sobre a execução } \\
\text { orçamentária, financeira } \\
\text { e patrimonial do } \\
\text { município, em desacordo }\end{array}$ & Irregularidades & $\begin{array}{l}\text { Obstrução, } \\
\text { exercício, } \\
\text { fiscalização. } \\
\text { Ausência, } \\
\text { documentação, } \\
\text { dados, sistema } \\
\text { informatizado, } \\
\text { execução } \\
\text { orçamentária, } \\
\text { execução } \\
\text { financeira, } \\
\text { execução } \\
\text { patrimonial. } \\
\text { Inobservância, } \\
\text { instrução } \\
\text { normativa, } \\
\text { TCEMG. } \\
\text { Obstrução, } \\
\text { exercício, } \\
\text { fiscalização, }\end{array}$ \\
\hline
\end{tabular}


Metodologia para a análise de assunto de acórdãos no contexto do controle externo: proposta de um modelo de leitura técnica

Ana Carolina Ferreira e Benildes Coura Moreira dos Santos Maculan

\begin{tabular}{|c|c|c|c|}
\hline $\begin{array}{c}\text { PARTE TEMÁTICA DO } \\
\text { ACÓRDÃO A } \\
\text { ANALISAR }\end{array}$ & QUESTIONAMENTOS & $\begin{array}{l}\text { CONCEITOS } \\
\text { ESSENCIAIS }\end{array}$ & $\begin{array}{c}\text { CONCEITOS } \\
\text { IDENTIFICADOS }\end{array}$ \\
\hline & $\begin{array}{c}\text { com as instruções } \\
\text { normativas do TCEMG. } \\
\text { Quais os argumentos? } \\
\text { Obstrução ao exercício } \\
\text { da fiscalização. } \\
\text { Desrespeito à instrução } \\
\text { normativa do TCEMG. } \\
\text { Ausência de documentos } \\
\text { necessários à } \\
\text { fiscalização. } \\
\text { Ação judicial de } \\
\text { obrigação de fazer, cujo } \\
\text { réu é o ex-prefeito. } \\
\text { Boletim de ocorrência } \\
\text { prévio de atentado ao } \\
\text { patrimônio público. } \\
\text { Violação aos princípios } \\
\text { da legalidade, } \\
\text { moralidade, transparência } \\
\text { e eficiência. } \\
\text { Entraves à regular } \\
\text { continuidade da } \\
\text { administração municipal. }\end{array}$ & & $\begin{array}{l}\text { TCEMG. ausência, } \\
\text { documentos. } \\
\text { Existência, ação } \\
\text { judicial, obrigação } \\
\text { de fazer, réu, ex- } \\
\text { prefeito. Existência, } \\
\text { boletim de } \\
\text { ocorrência, } \\
\text { atentado, } \\
\text { patrimônio público. } \\
\text { Violação, princípio } \\
\text { da legalidade, } \\
\text { princípio da } \\
\text { moralidade, } \\
\text { transparência, } \\
\text { princípio da } \\
\text { eficiência. Entrave, } \\
\text { continuidade, } \\
\text { administração } \\
\text { municipal. }\end{array}$ \\
\hline $\begin{array}{l}\text { VOTO } \\
\text { CONCLUSÃO/DECISÃO } \\
-\quad \text { (parte em que são } \\
\text { apresentadas as conclusões } \\
\text { do relator) }\end{array}$ & $\begin{array}{l}\text { Qual o entendimento? } \\
\text { Pela irregularidade dos } \\
\text { fatos denunciados. } \\
\text { Qual a decisão final? } \\
\text { Aplicação de multa. } \\
\text { Aplicação cumulativa da } \\
\text { sanção de declaração de } \\
\text { inabilitação do ex- } \\
\text { prefeito para o exercício } \\
\text { de cargo em comissão ou } \\
\text { função de confiança na } \\
\text { administração pública. } \\
\text { Determinação de } \\
\text { comunicação do } \\
\text { resultado da decisão ao } \\
\text { município de Araçuaí, } \\
\text { para as medidas } \\
\text { administrativas } \\
\text { necessárias. } \\
\text { Determinação de } \\
\text { comunicação do } \\
\text { resultado da decisão aos } \\
\text { chefes de poder do } \\
\text { Estado de Minas Gerais. } \\
\text { Determinação de } \\
\text { expedição de ofício à } \\
\text { procuradoria de justiça } \\
\text { da comarca de Araçuaí } \\
\text { sobre o resultado da } \\
\text { decisão. } \\
\text { Determinação à unidade }\end{array}$ & $\begin{array}{l}\text { Entendimento } \\
\text { do relator }\end{array}$ & $\begin{array}{l}\text { Irregularidade. } \\
\text { Aplicação, multa, } \\
\text { ex-prefeito, } \\
\text { declaração, } \\
\text { inabilitação, } \\
\text { exercício, cargo em } \\
\text { comissão, função } \\
\text { de confiança, } \\
\text { administração } \\
\text { pública. } \\
\text { Determinação, } \\
\text { comunicação, } \\
\text { decisão, município, } \\
\text { Araçuaí, chefe de } \\
\text { poder, estado, } \\
\text { Minas Gerais, } \\
\text { procuradoria de } \\
\text { justiça, comarca, } \\
\text { Araçuaí. } \\
\text { Determinação, } \\
\text { unidade técnica, } \\
\text { TCEMG, } \\
\text { monitoramento, } \\
\text { decisão. }\end{array}$ \\
\hline
\end{tabular}


Metodologia para a análise de assunto de acórdãos no contexto do controle externo: proposta de um modelo de leitura técnica

Ana Carolina Ferreira e Benildes Coura Moreira dos Santos Maculan

\begin{tabular}{|c|c|c|c|}
\hline $\begin{array}{c}\text { PARTE TEMÁTICA DO } \\
\text { ACÓRDÃO A } \\
\text { ANALISAR }\end{array}$ & QUESTIONAMENTOS & $\begin{array}{l}\text { CONCEITOS } \\
\text { ESSENCIAIS }\end{array}$ & $\begin{array}{c}\text { CONCEITOS } \\
\text { IDENTIFICADOS }\end{array}$ \\
\hline & $\begin{array}{l}\text { técnica de } \\
\text { monitoramento quanto ao } \\
\text { cumprimento da decisão. }\end{array}$ & & \\
\hline $\begin{array}{l}\text { ACÓRDÃO stricto sensu } \\
\text { (parte que veicula a } \\
\text { conclusão do colegiado de } \\
\text { julgadores) }\end{array}$ & $\begin{array}{c}\text { Quais são as } \\
\text { recomendações? } \\
\text { Não há, neste caso. } \\
\text { Qual o entendimento? } \\
\text { Pela irregularidade dos } \\
\text { fatos denunciados. } \\
\text { Qual a decisão final? } \\
\text { Aplicação de multa. } \\
\text { Aplicação cumulativa da } \\
\text { sanção de declaração de } \\
\text { inabilitação do ex- } \\
\text { prefeito para o exercício } \\
\text { de cargo em comissão ou } \\
\text { função de confiança na } \\
\text { administração pública. } \\
\text { Determinação de } \\
\text { comunicação do } \\
\text { resultado da decisão ao } \\
\text { município de Araçuaí, } \\
\text { para as medidas } \\
\text { administrativas } \\
\text { necessárias. } \\
\text { Determinação de } \\
\text { comunicação do } \\
\text { resultado da decisão aos } \\
\text { chefes de poder do } \\
\text { Estado de Minas Gerais. } \\
\text { Determinação de } \\
\text { expedição de ofício à } \\
\text { procuradoria de justiça } \\
\text { da comarca de Araçuaí } \\
\text { sobre o resultado da } \\
\text { decisão. } \\
\text { Determinação à unidade } \\
\text { técnica de } \\
\text { monitoramento quanto ao } \\
\text { cumprimento da decisão }\end{array}$ & $\begin{array}{l}\text { Decisão do } \\
\text { colegiado }\end{array}$ & $\begin{array}{l}\text { Irregularidade. } \\
\text { Aplicação, multa, } \\
\text { ex-prefeito, } \\
\text { declaração, } \\
\text { inabilitação, } \\
\text { exercício, cargo em } \\
\text { comissão, função } \\
\text { de confiança, } \\
\text { administração } \\
\text { pública. } \\
\text { Determinação, } \\
\text { comunicação, } \\
\text { decisão, município, } \\
\text { Araçuaí, chefe de } \\
\text { poder, estado, } \\
\text { Minas Gerais, } \\
\text { procuradoria de } \\
\text { justiça, comarca, } \\
\text { Araçuaí. } \\
\text { Determinação, } \\
\text { unidade técnica, } \\
\text { TCEMG, } \\
\text { monitoramento, } \\
\text { decisão. }\end{array}$ \\
\hline
\end{tabular}

SELEÇÃO DOS CONCEITOS / FRASE DE INDEXAÇÃO*: (1, 2) Denúncia, irregularidade, gestão, prefeitura, município, Araçuaí, formulação, Associação dos Amigos de Araçuaí. Realização, inspeção extraordinária, TCEMG. (3) Irregularidade. Obstrução, exercício, fiscalização, TCEMG. Ausência, documentação, dados, sistema informatizado, execução orçamentária, execução financeira, execução patrimonial. Inobservância, instrução normativa, TCEMG. (4) Obstrução, fiscalização. Existência, ação judicial, obrigação de fazer, réu, exprefeito. Existência, boletim de ocorrência, atentado, patrimônio público. Violação, princípio da legalidade, princípio da moralidade, transparência, princípio da eficiência. Obstrução, continuidade, administração municipal. (5) Aplicação, multa, ex-prefeito, declaração, inabilitação, exercício, cargo em comissão, função de confiança, administração pública. Determinação, comunicação, decisão, município, Araçuaí, chefe de poder, estado, Minas Gerais, procuradoria de justiça, comarca, Araçuaí. Determinação, unidade técnica, TCEMG, monitoramento, decisão.

SELEÇÃO DOS CONCEITOS REFERENTES ÀS RECOMENDAÇÕES / FRASE DE 
Ferreira (2017), (5) Decisão final. Os números indicados na parte final do exemplo de aplicação referem-se a essa ordem de citação.

Ademais, observa-se que os conceitos que constam na linha Seleção de conceitos / Frase de indexação ainda estão em linguagem natural. Para a padronização terminológica em termos da prática profissional, sugere-se a adoção de um tesauro ou vocabulário controlado. Por fim, na última linha do modelo, foram indicadas as fontes de informação jurídicas que fundamentaram a decisão.

\section{Considerações finais}

Este artigo apresentou o desenvolvimento de um Modelo de Leitura Técnica para acórdãos, em especial, para o Tribunal de Contas do Estado de Minas Gerais. Os conhecimentos da Biblioteconomia e da Ciência da Informação utilizados na concepção do modelo incluíram a abordagem da análise de assunto a partir de conceitos essenciais (GUIMARÃES, 1994; FUJITA; RUBI, 2006; MACULAN, 2011), o uso de estratégias de leitura para a compreensão textual, assim como a adoção de questionamentos para áreas específicas do conhecimento, conforme a proposta na NBR 12676 (ASSOCIAÇÃO BRASILEIRA DE NORMAS TÉCNICAS, 1992). Os aportes teóricos também englobaram a vertente teórica da compreensão do leitor, do texto e do contexto, conforme a literatura de Giasson (1993). Assim, foi possível o estudo do acórdão a partir de suas múltiplas variáveis, que incluem sua estrutura temática e especificidades enquanto documento jurídico; o leitor, que pode ser o operador do Direito ou o profissional-indexador, ambos com objetivos e motivações distintas para a leitura; o contexto do acórdão, que se refere ao controle externo. Para a construção do modelo de leitura, do campo jurídico, foram essenciais os conceitos de fontes de informação jurídicas, em especial, das questões estruturais do acórdão, assim como das competências constitucionais dos tribunais de contas.

Haja vista a carência de metodologias para se fazer a análise de assunto de um documento, problema de pesquisa que norteou a investigação, considera- 


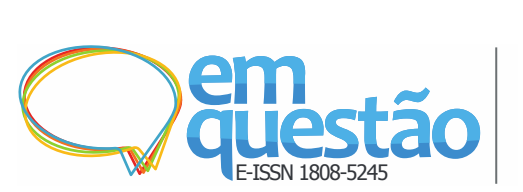

Metodologia para a análise de assunto de acórdãos no contexto do controle externo: proposta de um modelo de leitura técnica

Ana Carolina Ferreira e Benildes Coura Moreira dos Santos Maculan

se que o estudo relatado neste artigo ofereceu contribuições teóricometodológicas para a Biblioteconomia e a Ciência da Informação, ao sistematizar e objetivar a análise de assunto do acórdão a partir da definição das etapas e fases metodológicas para a realização da atividade.

Ademais, como a formação do bibliotecário jurídico é amplamente influenciada pela prática profissional, destaca-se que investigações no campo da representação temática de documentos jurídicos são importantes e necessárias. Ressalta-se, mais uma vez, que o modelo de leitura técnica apresentado neste artigo destina-se ao bibliotecário jurídico que, embora não seja especialista no domínio, detém as competências e abordagens metodológicas para organizar o conhecimento. Para isso, é fundamental a adoção de uma postura proativa do profissional, em termos de atualização e formação permanente em serviço.

\section{Referências}

AGNOLONI, T. et al. Annotation schema for legal doctrine: a case study on DoGi database. Italian Journal of Library and Information Science, Macerata, v. 4, n. 1, p. 227-249, Jan. 2013.

AL-ABDULKARIM, L.; ATKINSON, K.; BENCH-CAPON, T. Accommodating change. Artificial Intelligence and Law, New York, , v. 24, n. 4, p. 409-427, Dec. 2016.

\section{ASSOCIAÇÃO BRASILEIRA DE NORMAS TÉCNICAS. ABNT NBR} 12676: métodos para análise de documentos: determinação de seus assuntos e seleção de termos de indexação. Rio de Janeiro: ABNT, 1992.

ASSOCIAÇÃO BRASILEIRA DE NORMAS TÉCNICAS. ABNT NBR 6028: informação e documentação: resumo apresentação. Rio de Janeiro: ABNT, 2003.

ATIENZA, C. A. Documentação jurídica: introdução à análise e indexação de atos legais. Rio de Janeiro: Achiamé, 1979.

ATIENZA, C. A. Técnica de indexação de pronunciamentos judiciais. São Paulo, 1981.

BARBOSA NETTO, G.; CUNHA, C. A. Ementas e informativos nos tribunais de contas. Cuiabá: PubliContas, 2015. 


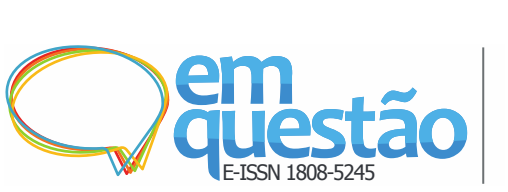

Metodologia para a análise de assunto de acórdãos no contexto do controle externo: proposta de um modelo de leitura técnica

Ana Carolina Ferreira e Benildes Coura Moreira dos Santos Maculan

BRAGA JÚNIOR, M. S. Proposta de modelo RBC para a recuperação inteligente de jurisprudência na Justiça Federal. 2001. Dissertação (Mestrado em Engenharia de Produção) - Programa de Pós-Graduação em Engenharia de Produção, Universidade Federal de Santa Catarina, Florianópolis, 2001.

BRASIL. Constituição da República Federativa do Brasil de 1988. Casa Civil: Subchefia para Assuntos Jurídicos. Brasília, 5 out. 1988.

BRASIL. Congresso Nacional. Lei n. 13.105, de 16 de março de 2015. Institui o Novo Código de Processo Civil. Disponível em:

http://www.planalto.gov.br/ccivil_03/_ato2015-2018/2015/lei/113105.htm. Acesso em: 25 abr. 2019.

BRASIL. Manual de indexação da justiça federal. Brasília: Conselho da Justiça Federal, 1996.

BRASIL. Superior Tribunal de Justiça. Manual do analista de jurisprudência. Brasília: Secretaria de Jurisprudência, 2002.

CÂMARA JÚNIOR, A. T. Indexação automática de acórdãos por meio de processamento de linguagem natural. 2007. Dissertação (Mestrado em Ciência da Informação) - Faculdade de Economia, Administração, Contabilidade e Ciência da Informação e Documentação, Universidade de Brasília, Brasília, 2007.

CAMPESTRINI, H. Como redigir ementas. São Paulo: Saraiva, 1994.

CHU, C. M.; O'BRIEN, A. Subject analysis: the critical first stage in indexing. Journal of Information Science, v. 19, n. 6, p. 439-454, 1993.

CINTRA, A. M. M. Estratégias de leitura em documentação. In: SMIT, J. W. (coord.). Análise documentária: a análise da síntese. Brasília: IBICT, 1987. p. 27-35.

DIAS, E. J. W.; NAVES, M. M. L. Análise de assunto: teoria e prática. 2. ed. rev. Brasília: Briquet de Lemos, 2013.

FAGUNDES, S. A. Leitura em análise documentária de artigos de jornais. 2001. Dissertação (Mestrado em Ciência da Informação) - Faculdade de

Filosofia e Ciências de Marília, Universidade Estadual Paulista, Marília, 2001.

FAIRTHORNE, R. A. Content analysis, specification and control. Annual Review of Information Science and Technology, [s.l.], v. 4, p. 73-109, 1969.

FARROW, J. A cognitive process model of document indexing. Journal of Documentation, London, v. 47, n. 2, p. 149-166, 1991. 


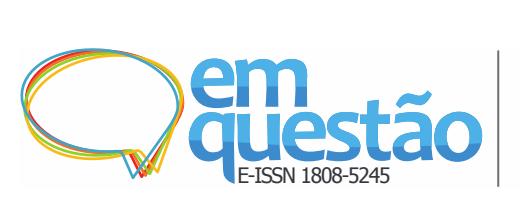

Metodologia para a análise de assunto de acórdãos no contexto do controle externo: proposta de um modelo de leitura técnica

Ana Carolina Ferreira e Benildes Coura Moreira dos Santos Maculan

FARROW, J. Propositional analysis and macrorules in indexing. Library

Review, Bingley, , v. 45, n. 1, p. 6-15, 1996.

FERNANDES, J. U. J. Tribunais de contas do Brasil: jurisdição e competência. 3. ed. rev. atual. e ampl. Belo Horizonte: Fórum, 2012.

FERREIRA, A. C. Análise de assunto da informação jurídica: proposta de um modelo de leitura técnica de acórdãos no contexto do controle externo. 2017. Dissertação (Mestrado em Gestão e Organização do Conhecimento) - Escola de Ciência da Informação, Universidade Federal de Minas Gerais, Belo Horizonte, 2017.

FRANCESCONI, E.; PERUGINELLI, G. Integrated access to legal literature through automated semantic classification. Artificial Intelligence and Law, New York, , v. 17, n. 1, p. 31-49, Mar. 2009.

FUJITA, M. S. L. A leitura documentária do indexador: aspectos cognitivos e linguísticos influentes na formação do leitor profissional. 2003. Tese (Livre Docência em Ciência da Informação) - Faculdade de Filosofia e Ciências, Universidade Estadual Paulista, Marília, 2003.

FUJITA, M. S. L. A representação documentária no processo de indexação com o modelo de leitura documentária para textos científicos e livros: uma abordagem cognitiva com protocolo verbal. Ponto de Acesso, Salvador, v. 7, n. 1, p. 42-66, abr. 2013.

FUJITA, M. S. L.; RUBI, M. P. Um modelo de leitura documentária para a indexação de artigos científicos: princípios de elaboração e uso para a formação de indexadores. DataGramaZero: revista de ciência da informação, [s.1.], v. 7, n. 3, 18 p., jun. 2006.

GIASSON, J. A compreensão na leitura. Lisboa: Asa, 1993.

GOMEZ, M. N. G. de. A representação do conhecimento e o conhecimento da representação: algumas questões epistemológicas. Ciência da Informação, Brasília, v. 22, n. 3, p. 217-222, set./dez. 1993.

GUALAZZI, E. L. B. Regime jurídico dos tribunais de contas. São Paulo: Ed. Revista dos Tribunais, 1992.

GUIMARÃES, J. A. C. Análise documentária em jurisprudência: subsídios para uma metodologia de indexação de acórdãos trabalhistas brasileiros. 1994. Tese (Doutorado em Ciências da Comunicação) - Escola de Comunicação e Artes, Universidade de São Paulo, São Paulo, 1994.

GUIMARÃES, J. A. C. Elaboração de ementas jurisprudenciais: elementos teórico-metodológicos. Brasília: Conselho da Justiça Federal, 2004. 


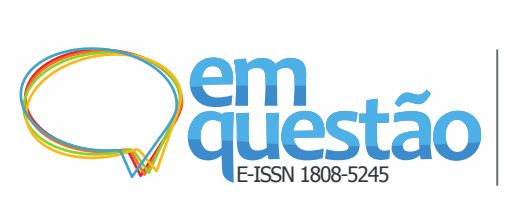

Metodologia para a análise de assunto de acórdãos no contexto do controle externo: proposta de um modelo de leitura técnica

Ana Carolina Ferreira e Benildes Coura Moreira dos Santos Maculan

HAFNER, C. D. Conceptual organization of case law knowledge bases. In:

INTERNATIONAL CONFERENCE ON ARTIFICIAL INTELLIGENCE AND LAW, 1., 1987, Boston. Proceedings [...]. New York: ACM Digital Library, 1987. p. 35-42.

HOUAISS, A.; VILLAR, M. S.; FRANCO, F. M. M. Dicionário Houaiss da língua portuguesa. Rio de Janeiro: Objetiva, 2007.

HUTCHINS, J. W. On the problem of aboutness in document analysis. Journal of Informatics, East Anglia, v. 1, n. 1, p. 17-35, Apr. 1977.

INGWERSEN, P. Information retrieval: interaction. London: Taylor Graham Publishing, 1992.

KATO, M. O aprendizado da leitura. 6. ed. São Paulo: Martins Fontes, 2007.

KLEIMAN, A. Texto e leitor: aspectos cognitivos da leitura. 2. ed. Campinas: Pontes, 1992.

KOBASHI, N. Y. A elaboração de informações documentárias: em busca de uma metodologia. 1994. Tese (Doutorado em Ciências da Comunicação) Escola de Comunicação e Artes, Universidade de São Paulo, São Paulo, 1994.

KOBASHI, N. Y.; FERNANDES, J. C. Pragmática linguística e organização da informação. In: ENCONTRO NACIONAL DE PESQUISA EM CIÊNCIA DA INFORMAÇÃO, 10., 2009, João Pessoa. Anais... João Pessoa: Ancib, 2009. v. 1. p. 1-14. Disponível em:

<http://enancib.ibict.br/index.php/enancib/xenancib/paper/viewFile/3172/2298>. Acesso em: 29 set. 2017.

LANCASTER, F. W. Indexação e resumos: teoria e prática. Brasília: Briquet de Lemos, 2004.

LARA, M. L. G. A representação documentária: em jogo a significação. 1993. Dissertação (Mestrado em Ciências da Comunicação) - Departamento de Biblioteconomia e Documentação, Universidade de São Paulo, São Paulo, 1993.

LASSWELL, H. Politics: who gets what, when, how. New York: The World Publishing Company, 1971.

LIMA, G. A. B. O.; MACULAN, B. C. M. S. Análise de assunto a partir de uma perspectiva histórica do ARIST. Ciência da Informação, Brasília, v. 41, n. 1, p. 22-35, jan./abr. 2014.

MAÇOLI, F. Análise documentária das ementas cíveis: uma experiência com acórdãos do Tribunal de Justiça do estado de São Paulo. 2005.

Dissertação (Mestrado em Ciência da Informação) - Programa de Pós- 


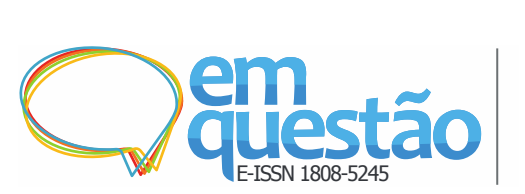

Metodologia para a análise de assunto de acórdãos no contexto do controle externo: proposta de um modelo de leitura técnica

Ana Carolina Ferreira e Benildes Coura Moreira dos Santos Maculan

Graduação em Ciência da Informação, Pontifícia Universidade Católica de Campinas, Campinas, 2005.

MACULAN, B. C. M. S. Taxonomia facetada navegacional: construção a partir de uma matriz categorial para trabalhos acadêmicos. 2011. Dissertação (Mestrado em Ciência da Informação) - Escola de Ciência da Informação, Universidade Federal de Minas Gerais, Belo Horizonte, 2011.

MANCUSO, R. C. Divergência jurisprudencial e súmula vinculante. 4. ed. São Paulo: Ed. Revista dos Tribunais, 2010.

MELO, M. A. O controle externo na América Latina. [São Paulo]: Instituto Fernando Henrique Cardoso, 2007.

MINAS GERAIS. Tribunal de Contas. Denúncia n. 837101. Denúncia. Irregularidades na gestão municipal. Realização de inspeção extraordinária na prefeitura municipal. Ausência de registros e documentos. Comprovada obstrução ao livre exercício do controle externo a cargo do tribunal de contas. Infração gravíssima. Inabilitação para o exercício de cargo em comissão ou função de confiança da administração pública estadual e municipal. Relator: Conselheiro Gilberto Diniz, 16 de maio de 2018.

MINAS GERAIS. Tribunal de Contas. Lei complementar $\mathbf{n}^{\mathbf{0}} \mathbf{1 0 2}$, de 17 de janeiro de 2008. Dispõe sobre a organização do Tribunal de Contas e dá outras providências. Belo Horizonte: Palácio da Liberdade, 2008.

MIRANDA, P. Comentários à Constituição de 1967: artigos 34-112. São Paulo: Ed. Revista dos Tribunais, 1967. v. 3.

MOLINARI, A. H. Indexação de acórdãos por meio de uma ontologia jurisprudencial populada a partir de um corpus jurídico real. 2011. Dissertação (Mestrado em Ciências na Área de Concentração Engenharia de Automação e Sistemas) - Programa de Pós-graduação em Engenharia Elétrica e Informática Industrial, Universidade Tecnológica Federal do Paraná, Curitiba, 2011.

MOURA, M. A. Leitor-bibliotecário: interpretação, memória e as contradições da intersubjetividade em processos de representação informacional. In: NAVES, M. M. L.; KURAMOTO, H. (org.). Organização da informação: princípios e tendências. Brasília: Briquet de Lemos, 2006. p. 22-35.

MOURÃO, L. A.; MASTRO, B. T. Manual de implantação: serviço de documentação jurídica. 2. ed. São Paulo: Cepam, 1989.

NADER, P. Introdução ao estudo do Direito. 36. ed. rev. atual. Rio de Janeiro: Forense, 2014. 


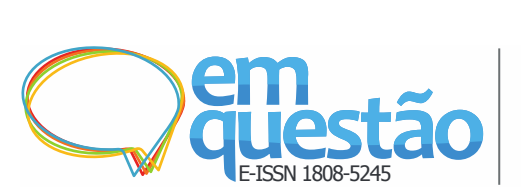

Metodologia para a análise de assunto de acórdãos no contexto do controle externo: proposta de um modelo de leitura técnica

Ana Carolina Ferreira e Benildes Coura Moreira dos Santos Maculan

NAVES, M. M. L. Fatores interferentes no processo de análise de assunto. 2000. Tese (Doutorado em Ciências da Informação) - Escola de Ciência da Informação, Universidade Federal de Minas Gerais, Belo Horizonte, 2000.

NEVES, D. A. B. Representação temática da informação e mapas cognitivos: interações possíveis. Informação \& Sociedade: estudos, João Pessoa, v. 22, p. 39-47, 2012. Número especial.

OLIVEIRA, S. R. Recuperação inteligente de jurisprudência: uma avaliação do Raciocínio Baseado em Casos aplicado à recuperação de jurisprudências no Tribunal Eleitoral do Distrito Federal. 2008. Dissertação (Mestrado em Ciência da Informação) - Programa de Pós-Graduação em Ciências da Informação, Universidade de Brasília, Brasília, 2008.

PALIWALA, A. Rediscovering artificial intelligence and law: an inadequate jurisprudence? International Review of Law, Ar Rayyan, v. 30, n. 3, p. 107114, Oct. 2016.

PIMENTEL, K. M. C. Ementas jurisprudenciais: manual para identificação de teses e redação de enunciados. Curitiba: Juruá, 2015.

REALE, M. Lições preliminares de direito. 21. ed. São Paulo: Saraiva, 1994.

RIBEIRO, S. F. Sistema de conhecimento para gestão documental no setor judiciário: uma aplicação no Tribunal Regional Eleitoral de Santa Catarina. 2010. Dissertação (Mestrado em Engenharia e Gestão do Conhecimento) - Programa de Pós-Graduação em Engenharia e Gestão do Conhecimento, Universidade Federal de Santa Catarina, Florianópolis, 2010.

RUMELHART, D. E. Schemata: the building blocks of cognition. In: SPIRO, R. J. et al. (org.). Theoretical issues in reading comprehension. Nova Jersey: Lawrence Erlbaum, 1980.

SILVA, A. G. Leitura documentária das fontes de informação jurídica. 2008. Dissertação (Mestrado em Ciência da Informação) - Escola de Comunicação e Artes, Universidade de São Paulo, São Paulo, 2008.

STRANIERI, A. et al. A hybrid rule: neural approach for the automation of legal reasoning in the discretionary domain of family law in Australia. Artificial Intelligence and Law, New York, , v. 7, n. 2-3, p. 153-183, Sept. 1999.

TAAL, A. et al. Cognitive computing and proposed approaches to conceptual organization of case law knowledge bases: a proposed model for information preparation, indexing, and analysis. Artificial Intelligence and Law, New York, v. 24, n. 4, p. 347-370, Dec. 2016. 
Metodologia para a análise de assunto de acórdãos no contexto do controle externo: proposta de um modelo de leitura técnica

Ana Carolina Ferreira e Benildes Coura Moreira dos Santos Maculan

TÁLAMO, M. F. G. M. Elaboração de resumos. São Paulo: Escola de Comunicação e Artes, 1987.

VAN DIJK, T. A. News analysis: case studies of international and national News in the press. Hillsdale: Lawrence Erlbaum Associates, 1988.

VAN DIJK, T. A.; KINTSCH, W. Strategies of discourse comprehension. New York: Academic Press, 1983.

UNITED NATIONS INFORMATION SYSTEM IN SCIENCE AND TECHNOLOGY. Princípios de indexação. Revista da Escola de

Biblioteconomia da UFMG, Belo Horizonte, v. 10, n. 1, p. 83-94, Mar. 1981.

VERHEIJ, Bart. Formalizing value-guided argumentation for ethical systems design. Artificial Intelligence and Law, New York, , v. 24, n. 4, p. 387-407, Dec. 2016.

VIGOTSKY, L. S. A construção do pensamento e da linguagem. 2. ed. São Paulo: Martins Fontes, 2009.

\title{
Methodology for the analysis of rulings in the context of external control: proposal for a technical reading model
}

\begin{abstract}
This study presents part of the results of a master's degree research that investigated the lack of methodologies in the literature of Librarianship and Information Science (IS) for the subject analysis of legal ruling documents. As the analysis of rulings is essentially subjective, systematized methodological procedures are necessary to make it more objective and thus, obtain greater consistency in the thematic representation of information. In this context, the aim of the study was to develop a methodology for systematizing the rulings analysis to minimize the subjectivity that is inherent to the analysis process of this type of document during technical reading. This is an exploratory, qualitative, applied case study conducted at the Tribunal de Contas do Estado de Minas Gerais (Court of Audit of the state of Minas Gerais). Based on theoretical-conceptual contributions of Librarianship, Information Science and Law, a model for the technical reading of rulings from the court of audit was developed. The model's framework consisted of the document thematic structure, identification of essential concepts based on questions, use of cognitive and metacognitive reading strategies, and adoption of categories of thematic analysis defined by Guimarães. The results of the study indicate that the systematized practice of subject analysis can facilitate the analysis process when the methodological procedures for the indexer carrying out the activity are clearly defined.
\end{abstract}

Keywords: Subject analysis. Indexing. Technical reading model. Reading strategies. Rulings. Court of audit. 
Metodologia para a análise de assunto de acórdãos no

Recebido: 16/07/2018

Aceito: 14/11/2018

${ }^{1}$ O método é um "Procedimento, técnica ou meio de se fazer alguma coisa, de acordo com um plano [...]" (HOUAISS; VILLAR; FRANCO, 2007, p. 1910) e a metodologia é a "Parte de uma ciência que estuda os métodos aos quais ela própria recorre." (HOUAISS; VILLAR; FRANCO, 2007, p. 1911).

${ }^{2}$ A expressão controle externo se refere ao exercício da fiscalização e do controle exercidos pelos tribunais de contas em relação aos recursos públicos.

${ }^{3}$ As ementas constituem tipos de resumos jurisprudenciais e são constituídas por duas partes principais: a verbetação e o dispositivo. A primeira refere-se a um conjunto de palavras-chave ou expressões que refletem o conteúdo do documento jurisprudencial. Já o dispositivo contém "[...] a regra resultante do julgamento do caso concreto." (CAMPESTRINI, 1994, p. 8).

${ }^{4}$ A Teoria Tridimensional do Direito defende a existência de três aspectos básicos em todo fenômeno jurídico: fato, valor e a norma. Assim, “[...] tais elementos ou fatores (fato, valor e norma) não existem separados uns dos outros, mas coexistem numa unidade concreta, [...] de tal modo que a vida do Direito resulta da interação dinâmica e dialética dos três elementos que a integram." (REALE, 1994, p. 65, grifos do autor).

5 A frase de indexação é também denominada resumo estruturado nos manuais de indexação de documentos jurídicos. Essa frase de indexação e/ou resumo estruturado, que não se confunde com aquele resumo objeto da NBR 6028 (ASSOCIAÇÃO BRASILEIRA DE NORMAS TÉCNICAS, 2003), objetiva organizar, de forma lógica e compreensível ao leitor, os conceitos extraídos do documento. Destaca-se, porém, que esse tipo de resumo, intitulado estruturado, é um elemento característico da representação temática de documentos jurídicos, como os acórdãos e as leis. 